\title{
Advanced Hot Section Materials and Coatings Test Rig
}

Report:

Reporting Period Start Date:

Reporting Period End Date:

Principal Author:

Report Date:

DOE Award Number:
Quarterly Report

$1 / 01 / 04$

$3 / 31 / 04$

Scott Reome/Dan Davies

30 April 2004

DE-FC26-03NT41888

Florida Turbine Technologies, Inc.

140 Intracoastal Pointe Drive, Suite 301

Jupiter, FL 33477

"This report was prepared as an account of work sponsored by an agency of the United States Government. Neither the United States Government no any agency thereof, nor any of their employees, makes any warranty, express or implied, or assumes any legal liability or responsibility for the accuracy, completeness, or usefulness of any information, apparatus, product, or process disclosed, or represents that its use would not infringe privately owned rights. Reference herein to any specific commercial product, process, or service by trade name, trademark, manufacturer, or otherwise does not necessarily constitute or imply its endorsement, recommendation, or favoring by the United States Government or any agency thereof. The views and opinions of authors expressed herein do not necessarily state or reflect those of the United States Government or any agency thereof." 


\begin{abstract}
:
The Hyperbaric Advanced Hot Section Materials \& Coating Test Rig program provides design and implementation of a laboratory rig capable of simulating the hot gas path conditions of coalgas fired industrial gas turbine engines. The principal activity during this reporting period were the evaluation of syngas combustor concepts, the evaluation of test section concepts and the selection of the preferred rig configuration.
\end{abstract}

\title{
Table of Contents:
}

Introduction

Executive Summary

Experimental

Results and Discussion

Conclusion

\section{List(s) of Graphical Materials:}

Figure 1. Radial jet combustor concept

Figure 2. Test specimen orientations with equivalent inlet airflow (0.4pps @ 3000F, 350psi)

Figure 3. Test section concept comparison of Key Success Factors (KSFs) 


\section{INTRODUCTION}

This is the second quarterly report of technical progress on contract \# DE-FC26-03NT41888 for the Hyperbaric Advanced Hot Section Materials \& Coating Test Rig in which Phase I was awarded to Florida Turbine Technologies (FTT) in October, 2003. The objectives of Phase I are to complete conceptual design studies, downselect a configuration, and execute a detail design of the rig test section. Additional goals of this phase include conceptual definition of auxiliary systems and facilities, and preparing plans for permitting and implementation. In Phase II, a prototype test section will be fabricated and tested, and designs for auxiliary systems and facilities completed, and rig hardware fabricated, equipment purchased, and test facilities constructed. Phase III completes the project with the installation of the rig, checkout and demonstration.

\section{EXECUTIVE SUMMARY}

The Hyperbaric Advanced Hot Section Materials \& Coating Test Rig Phase I activity continued this quarter. Florida Turbine Technologies is designing and is planning the implementation of a laboratory rig capable of simulating the hot gas path conditions of coal gas fueled industrial gas turbine engines. Potential uses of this rig include investigations into environmental attack of turbine materials and coatings exposed to syngas, erosion, and thermal-mechanical fatigue.

The principle activities during the current period were the completion of conceptual design studies of syngas combustor concepts, and conceptual design of various test section configurations initiated during the previous period. An FTT internal review was held to select the preferred rig configuration, and to establish design goals for the detailed design to be initiated next quarter. Based on this recommendation, a coherent, overall program plan, leveraging funding available from the Department of Energy and the Department of Defense was prepared.

\section{EXPERIMENTAL}

This project provides for the design and implementation of a laboratory rig capable of simulating the hot gas path conditions of coal gas fired industrial gas turbine engines. Potential uses of this rig include investigations into environmental attack of turbine materials and coatings exposed to syngas, erosion, and thermal-mechanical fatigue. Because the program is currently in the concept development stage, no experimental results are available at this time.

\section{RESULTS AND DISCUSSION}

The principle activities during the current period were the completion of conceptual design studies of syngas combustor concepts and of various test section concepts initiated during the previous period. An FTT internal review was held to select the preferred rig configuration, and to establish design goals for the detailed design to be initiated next quarter. Based on this

This document contains information proprietary to Florida Turbine Technologies, Inc. This information is not to be reproduced, transmitted, disclosed or used in whole or in part, without the written authorization of Florida Turbine Technologies, Inc. 
recommendation, a coherent, overall program plan, leveraging funding available from the Department of Energy and the Department of Defense was prepared. A summary of activities in each of these tasks is summarized below.

Conceptual design studies for a rig combustor fueled by syngas were conducted. Two approaches were considered for the burner: 1) scaling an existing natural gas burner modified to burn syngas, and 2) developing a new, rig unique combustor with gas nozzles sized for syngas and natural gas. For the existing design approach, a Siemens V64.3A burner was considered. In this $70 \mathrm{MW}$ engine, airflow to an individual burner is over $5 \mathrm{lb} / \mathrm{sec}$, significantly oversized for an unscaled application in this rig having a target total airflow below $0.5 \mathrm{lbs} / \mathrm{sec}$. Scaling the burner geometry to this smaller airflow is possible, however, such a significant redesign is not expected to yield similar performance, stability and emissions without substantial development. The rig-unique combustor approach is to adapt an existing FTT radial jet combustor design to operate on syngas. This combustor was designed under a USAF Phase I SBIR (Contract \#F33615-03-M-2400) for use in a Proof-of-Concept demonstration rig of an alternate materials test rig concept. This air-cooled combustor design is shown in Figure 1. Sized for $0.5 p p s$ airflow, the combustor has swirlers oriented radially around the outer liner to mix $30 \%$ of the airflow with fuel from the 6 gas nozzles. To convert this design from natural gas to syngas operation, the 18 tip holes on these nozzles need to be made larger (from 0.016 dia to 0.024 ).

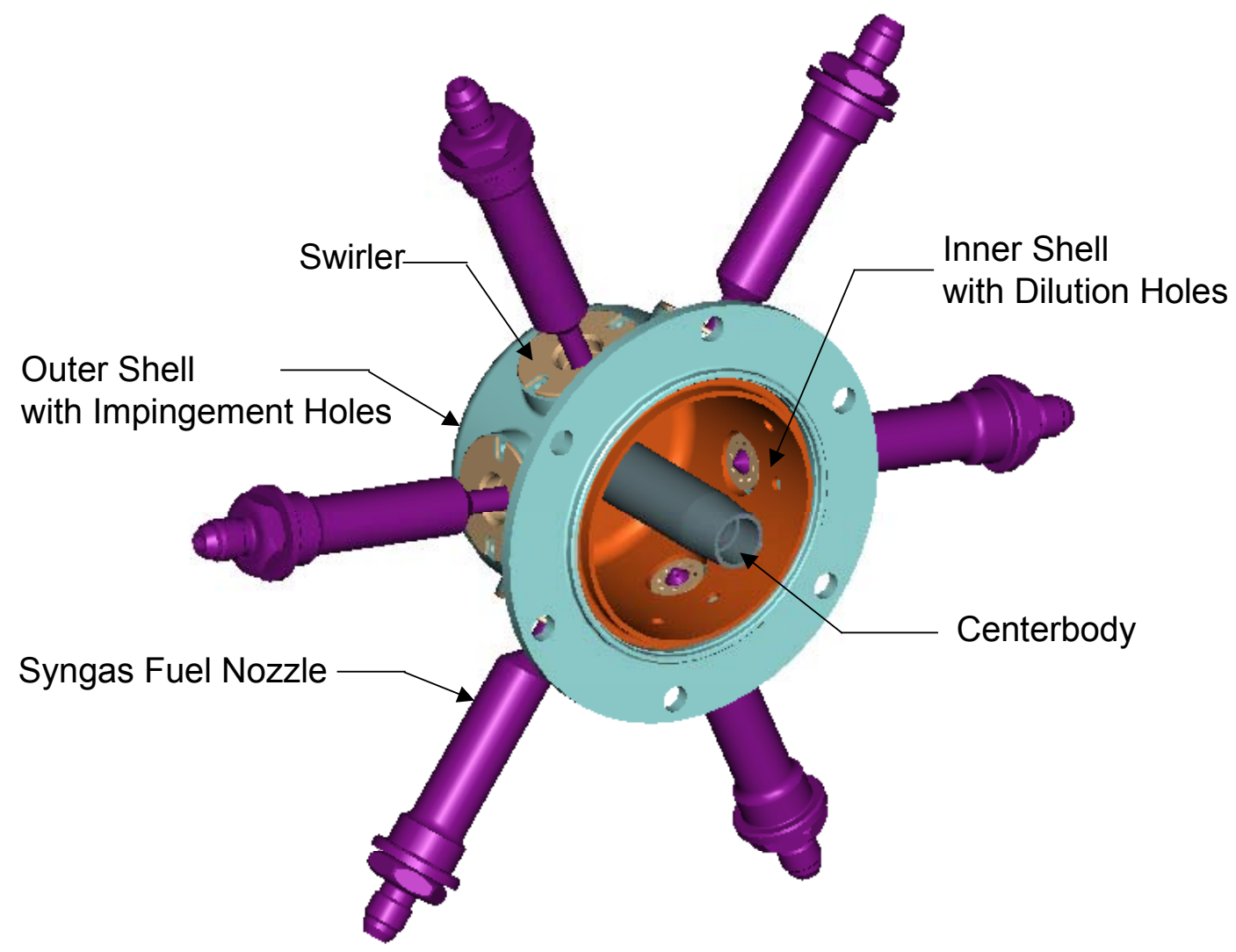

Figure 1. Radial jet combustor concept

This document contains information proprietary to Florida Turbine Technologies, Inc. This information is not to be reproduced, transmitted, disclosed or used in whole or in part, without the written authorization of Florida Turbine Technologies, Inc. 
Concept development continued on a variety of test section concepts during this period. As an alternative to the rig configuration which orients the test specimens axially with the hot gas flow (concept derived under Phase I of DOE SBIR (Grant No. DE-FG02-03ER83660), conceptual designs in this program focused on configurations that orient the test specimen transverse to the hot gas flow. The transverse orientation is of interest because it may provide a better simulation of the gas turbine environment in which hot gas impinges on airfoil leading edges then accelerates and flows across the airfoil surface.

Functional and performance criteria for the transversely mounted specimen test section concepts were selected to simulate actual IGT loads:

$\begin{array}{ll}\text { Hot gas temperature: } & 3000 \mathrm{~F} \\ \text { Gas pressure: } & 350 \mathrm{psi} \\ \text { Coolant temperature: } & 775^{\circ} \mathrm{F} \\ \text { TMF mechanical stress: } & 0-50 \mathrm{ksi} \\ \text { Rig Total Airflow } & 0.4 \mathrm{pps}\end{array}$

Three rig configurations were studied, each with test specimens oriented transverse to the hot gas flow (see Figure 2). A fourth configuration, developed in Phase I of the DOE SBIR, has the test specimen aligned axially with the hot gas flow is also shown. All configurations are based on $0.5 \mathrm{sq}$ in cylindrical specimens with internally air cooling, exposed to hot gas on the external surface. Specimen length was assumed to be 0.5 in. The number of specimens included in each configuration is based on an equivalent airflow to the test section. For comparison purposes, a baseline airflow of 0.4 pps was assumed.
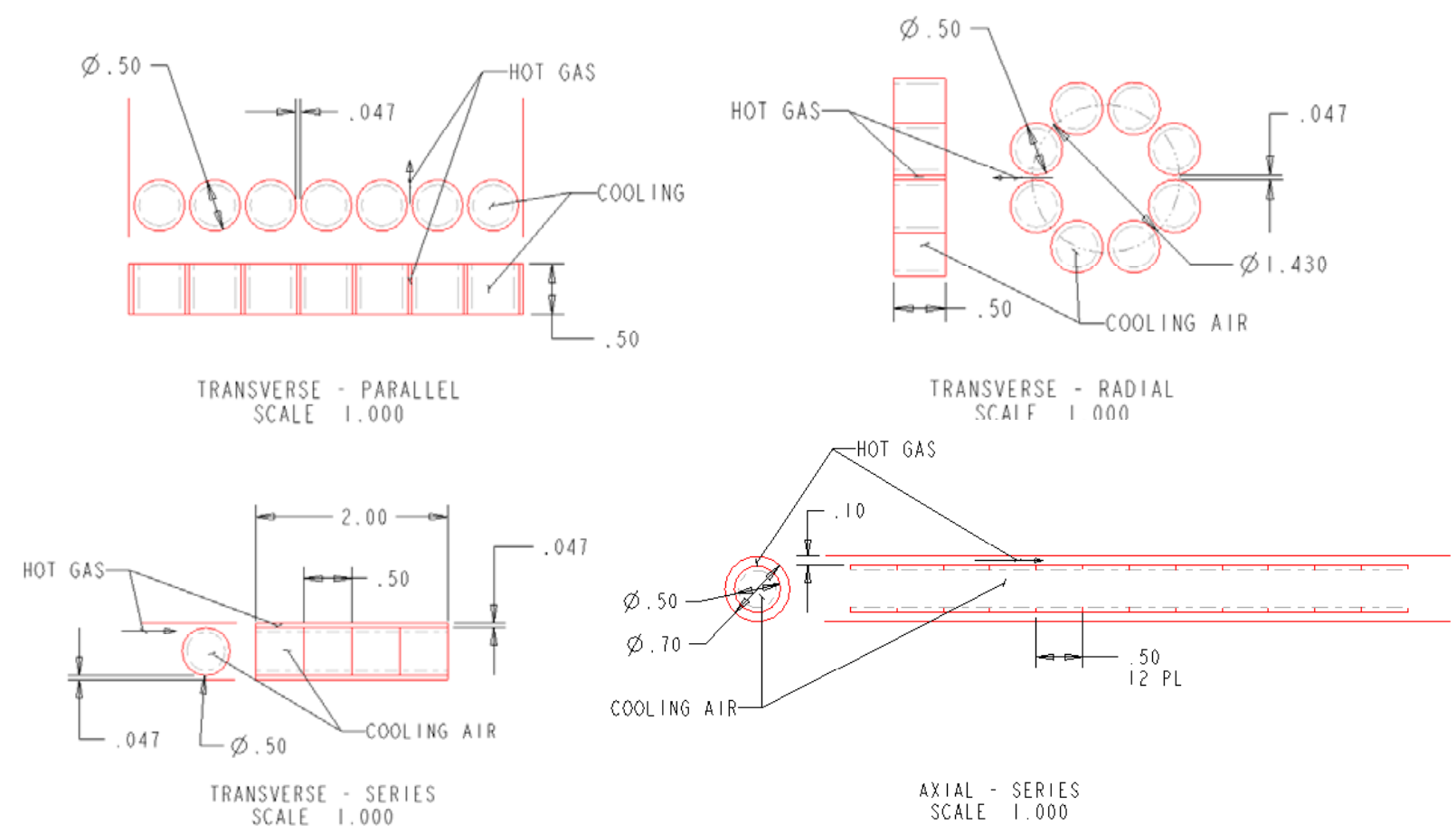

Figure 2. Test specimen orientations with equivalent inlet airflow (0.4pps @ 3000F, 350psi)

This document contains information proprietary to Florida Turbine Technologies, Inc. This information is not to be reproduced, transmitted, disclosed or used in whole or in part, without the written authorization of Florida Turbine Technologies, Inc. 
A description of the four test section configurations follows:

Configuration 1: Transverse - Parallel

Combustor flow is ducted through a circular to rectangular transition. Cylindrical specimens are positioned parallel to each other within a rectangular duct.

Configuration 2: Transverse - Series

Combustor flow is ducted through a circular to rectangular transition. Cylindrical specimens are positioned in series with each other (end-to-end) within a rectangular duct.

Configuration 3: Transverse - Radial

Combustor flow is directed into the center of a ring of cylindrical specimens. Gaps between adjacent specimens allow hot gas to flow radially outward.

Configuration 4: Axial - Series

Combustion flow is directed into an annular area formed by a cylindrical containment vessel and the outer wall of cylindrical test specimens, positioned in series with each other (end-toend).

For the purpose of comparing these different configurations, Key Success Factors (KSFs) were identified for the materials test rig design. KSFs are scored 5=best to 1=worst. Weighing factors are also assigned for each KSF; 3=most important, 1=least important.

- Number of test specimens

The number of individual material test specimens that can be included in the same test. A rig design having the greatest number of specimens, without excessive penalty to other KSFs is preferred. Weighing factor: 3

- Thermal Loading

Heat transfer to the test specimens should be uniform, predicable, measurable, and representative of thermal loading on gas turbine components. Weighing factor: 3

- Mechanical Loading

For thermal-mechanical fatigue (TMF) testing, a tensile load is applied to the test specimens. The load should be uniform, predicable, measurable, and representative of tensile loading on rotating gas turbine components. Weighing factor: 2

- Leakage

Air loss, bypassing the intended flow circuit should be minimized. Includes loss of cooling air between specimens and the rig walls or between specimens and adjoining specimens. Also includes loss of air between the combustor and test section. Weighing factor: 2

- Simplicity

In maximizing rig performance and reliability, simplicity can be maintained in regard to attributes such as number and cost of parts, test set-up time and procedures, reliability and safety. Weighing factor: 1

An analysis of the four potential rig configurations relative to the KSFs yielded the results shown in Figure 3.

This document contains information proprietary to Florida Turbine Technologies, Inc. This information is not to be reproduced, transmitted, disclosed or used in whole or in part, without the written authorization of Florida Turbine Technologies, Inc. 


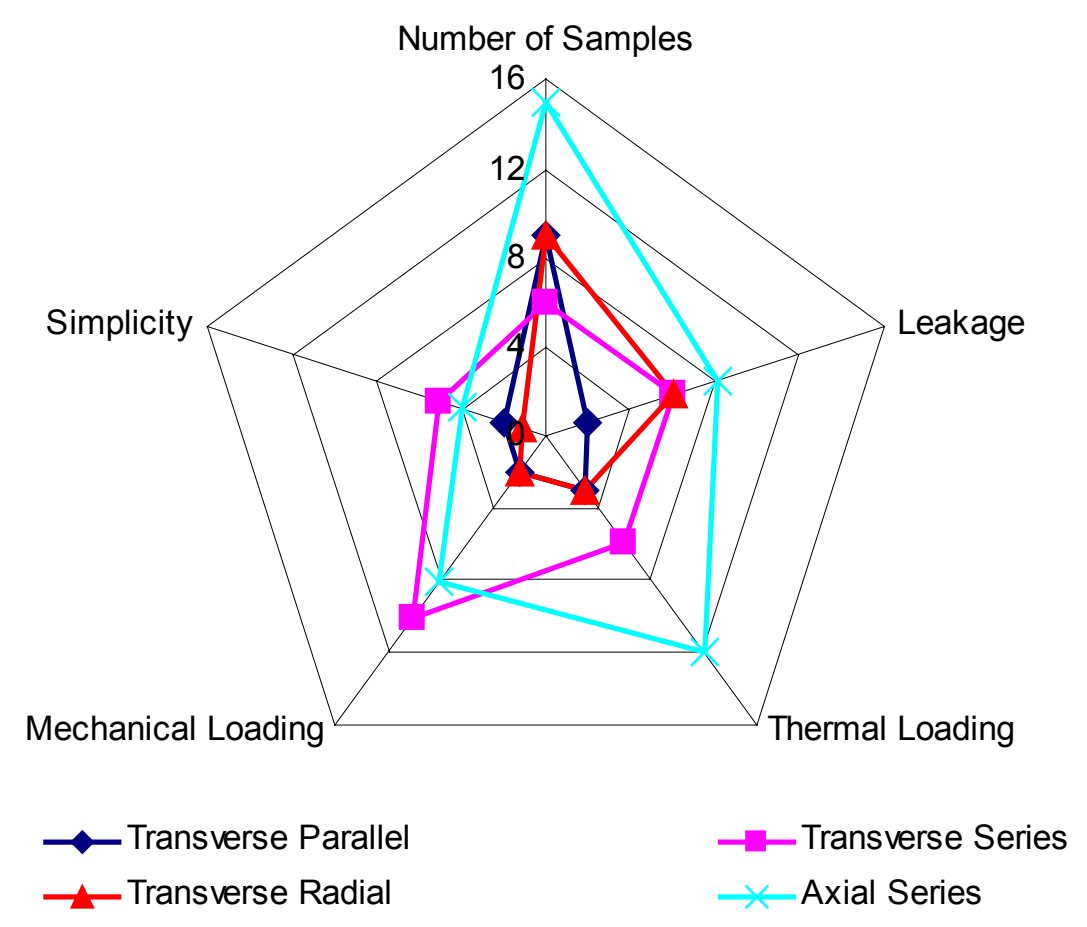

Figure 3. Test section concept comparison of Key Success Factors (KSFs)

The axial - series arrangement was identified as the preferred configuration for the materials test rig. The transverse - series configuration shown to be slightly better on two KSFs, but significantly worse on the other three. Transverse - parallel, and transverse - radial scored lower than axial - series on all other KSFs.

All three transversely arranged test specimens were found inferior in the thermal loading comparison. The disadvantage of these transverse arrangements is that the flow over the cylinder is complex and difficult both to predict and to experimentally measure. The fundamental issue with aerodynamics and heat transfer from flow around a single cylinder in cross flow is that there is a the large variation in the boundary layer around the cylinder. Unlike with the well behaved flow in a tube as in the axial - series configuration, pressure gradients that result from cross flow over the tube result in flow separation. The location where this separation occurs is a function of Reynolds number and flow rate. For a fixed test section geometry and sample size, the heat transfer characteristics will vary depending on flow rate. This makes analytical scaling difficult and leads to large errors in data reduction. At high Reynolds numbers there will be two inflection points in the specimen heat transfer coefficient over the cylinder. The first inflection comes from a transition from laminar to turbulent flow, and the second is related to the separation point on the cylinder. Heat flux through the material, thus the substrate and coating temperatures, will vary with the local heat transfer coefficient. Empirical data is available from which the average and local variations in heat transfer can be calculated, however, in the tests planned for this rig, such variation is considered highly undesirable.

This document contains information proprietary to Florida Turbine Technologies, Inc. This information is not to be reproduced, transmitted, disclosed or used in whole or in part, without the written authorization of Florida Turbine Technologies, Inc. 


\section{FTT PROPRIETARY}

DE-FC26-03NT41888: Hyperbaric Advanced Hot Section Materials and Coating Test Rig

page 8

Specimen rotation has been considered as a potential solution to produce a more uniform heat flux around the specimen. The speed of rotation needs to be faster than the thermal time constant for the material system being tested. If the rate of rotation is too great, however, further heat transfer variation may be induced due to aerodynamic effects of rotating cylinders in crossflow.

\section{CONCLUSION}

Based upon the results of the combustor and test section conceptual design effort, an FTT internal review was held to downselect to a single, preferred rig configuration. The radial jet combustor was selected because it can be easily modified to burn syngas, and the axial-series test section configuration was selected as having the minimum per specimen test cost with the most desirable thermal loading. 